\title{
The contribution of human sciences to the challenges of contemporary psychiatry
}

\author{
A contribuição das ciências humanas para os desafios da psiquiatria \\ contemporânea
}

Guilherme Messas, ${ }^{1}$ K. W. Fulford, ${ }^{2,3}$ Giovanni Stanghellini ${ }^{4,5}$

\begin{abstract}
One of the unique characteristics of psychiatry is its intimate relationship with the human sciences. Psychiatry, perhaps more than other medical specialties, requires the support of knowledge originating in various fields, including, on the one hand, the natural sciences, notably the cognitive and neurosciences, and, on the other, the human sciences, including philosophy, sociology, and anthropology. The twin dependence of psychiatry on both the natural and human sciences reflects, as American neuroscientist and psychiatrist Nancy Andreasen ${ }^{1,2}$ has pointed out, its strong personcentered nature as a clinical discipline. It is because psychiatry is concerned above all not with brains or other bodily parts or subsystems but with persons that it requires methodologies from the human as well as the natural sciences. Psychiatry is in this respect no less scientific than any other branch of medicine. There have after all been many potentially exciting developments in the neurosciences in recent decades relevant to the diagnosis and management of mental disorders. But if psychiatry is to retain its validity as a unique personcentered clinical discipline, it is now more than ever important that it stands ready to incorporate insights from the human sciences alongside those from the natural sciences. ${ }^{3}$
\end{abstract}

The identification of the close relationship between the human sciences and psychiatry dates from the second decade of the 20th century, with the pivotal work of Karl Jaspers entitled General Psychopathology. ${ }^{4}$ In this volume, plus two closely related papers published in the same year, ${ }^{5,6}$ Jaspers argued that it is fundamental for psychiatrists to understand the methods by which their data are obtained, and that empirical results acquire validity only to the extent of the possibilities and limits of their underpinning methodologies. The methods of psychiatric science, Jaspers argued, drawing on the Methodenstreit, a 19th-century philosophical debate about methods in the human sciences, require insights equally from the human and from the natural sciences.

Jaspers' conclusion, broadly understood, remains unshaken to this day. ${ }^{7}$ However, the relationship between the human sciences, the natural sciences, and psychiatry has shifted periodically over the one century elapsed since Jaspers' first work. ${ }^{8}$ The pendulum, which in the last three decades emphasized the natural sciences, is now swinging back towards the human sciences. The challenge, therefore, that psychiatry now faces, is to incorporate findings from the human sciences alongside those of the natural sciences in a fully integrated approach to the delivery of comprehensive care

\footnotetext{
${ }^{1}$ Faculdade de Ciências Médicas da Santa Casa de São Paulo, São Paulo, SP, Brazil. ${ }^{2}$ Philosophy Faculty and Collaborating Centre for Values-Based Practice, St. Catherine's College, University of Oxford, Oxford, UK. ${ }^{3}$ University of Warwick, Warwick, UK. ${ }^{4}$ Dipartimento di Scienze Psicologiche della Salute e del Territorio (DisPuTer), Università degli Studi "G. d'Annunzio," Chieti, Italy. ${ }^{5}$ Universidad Diego Portales, Santiago, Chile.

Submitted Sep 04 2017, accepted for publication Sep 082017.

Suggested citation: Messas G, Fulford KW, Stanghellini G. The contribution of human sciences to the challenges of contemporary psychiatry. Trends Psychiatry Psychother. 2017;39(4):229-231. http://dx.doi.org/10.1590/2237-6089-2017-0111
} 
services. A key step towards understanding how this is to be done is to define the distinctive contributions of the human sciences to contemporary person-centered clinical care. We believe there are currently no less than three such contributions.

Investigation of values. The investigation of values brings together the two major western philosophical systems, namely, Anglo-American analytic philosophy and continental philosophy, including phenomenology. The joint resources of these two great traditions have been considered increasingly important to personcentered care in all areas of medicine but especially in the improvement of mental health practice, where their contributions extend from assessment to treatment and nosography. Diagnosing a mental disorder is dependent not only on careful clinical observations (and sometimes other empirical resources derived from the natural sciences) but also on an - often tacit - understanding of human existence and the establishment of a scale of philosophical-anthropological values expressed in an epistemology. 9,10

The incorporation of values research by psychiatry, as the example of nosography shows, does not mean rejecting good scientific evidence obtained by rigorous scientific methods. The human sciences here as in all other areas of clinical decision-making are not intended to rival the natural sciences but rather to sit alongside them. "Values-based practice," the term used in the UK (for an example in surgery, see Websites section after References), is a partner to "evidence-based practice." Person-centered care, this approach recognizes, depends on an array of resources in which knowledge based on evidence and knowledge based on values work in synergy. ${ }^{11}$

Psychopathology. The impossibility of a neutral and universal diagnostic act, independent of the observer, points to the vital importance of psychopathology as an autonomous science, dependent on methods originating equally in the human and in the natural sciences, as set out and defended by Jaspers. Rating scales and other resources of the natural sciences have an important place (for example in comparative epidemiology). But at a personal level, mental health diagnosis depends critically on the interpersonal contact between the psychiatrist and his/her patient: this, as Jaspers showed, is supported by empathy and other resources for creating relationships derived from the human sciences. The affections, emotions, representations, and narratives that arise in the doctor-patient relationship are the primordial input (the "data") from which a psychopathological diagnosis is validated.

The recognition of psychopathology as a distinct discipline fundamental to clinical psychiatry requires the corresponding recognition of a distinct conception of scientific objectivity, different from (though complementary to) that of somatic specialties. This is where some of the deepest conceptual challenges for psychiatry from the philosophy of science arise. Psychopathological objectivity must take into account subjective experiences. Subjectivity and intersubjectivity are not experiences that are inaccessible to objective scientific knowledge; on the contrary, they are part of an objectivity of a larger and more complex kind. ${ }^{12}$ Psychopathology, as the discipline that assesses and makes sense of abnormal human subjectivity and intersubjectivity, should be at the heart of psychiatry. It should be a basic educational prerequisite in the curriculum for mental health professionals and a key element of the shared intellectual identity of clinicians and researchers in this field. ${ }^{13}$

In respect of these and other challenges from the philosophy of science, as with the challenges of values considered above, psychiatry is not alone as a medical discipline. The challenges are perhaps particularly acute in psychiatry. But they are there in principle for any area of person-centered clinical care. Psychopathological science assumes that all pathological mental experience must be understood from the point of view of the dialectic between the disorder and the totality of the personality. ${ }^{14}$ This may appear different from its counterparts in other medical specialties, in which a body or system can be singled out for diagnosis from the organism as a whole. Such "singling out" certainly happens. But it is precisely this "singling out" that person-centered clinical care, in surgery no less than in psychiatry, seeks to avoid. The psychopathologist needs to identify the global meaning that the pathological experience assumes for mental life. Psychopathological diagnosis must therefore take place on two simultaneous and interchangeable levels: the detection, first, of the essence of the pathological experience, ${ }^{15}$ and then, second, of its meaning for the person in whom it arises. ${ }^{16}$ Best practice in person-centered clinical care requires the same two levels of understanding in any other branch of medicine as well.

Individualization of treatment. The individualization of treatment (person-centered clinical care as we have called it here) is thus a natural consequence of the two themes discussed above. At a time of growing power and resources of the natural sciences in medicine, this is ethically as well as practically vital in the defense of the irreducible value of an individual human life. Scientific evidence obtained by epidemiological methods and clinical trials - gathered under good practice guidelines - must be guided by the 
principle of individualization, making psychopathology the basis of clinical activity in psychiatry. ${ }^{17}$ Precisely the same principle of "tailor-made" clinical practice is recognized in the best of scientific practice in other areas of person-centered medicine. Evidence-based guidelines for treatment, for example, produced by UK's National Institute for Health and Care Excellence (NICE), emphasize the importance of clinicians using the guidelines alongside the "needs, wishes and values of their individual patients and service users" (see Websites section after References).

In medicine as a whole, therefore, knowledge obtained in a general manner may no longer be considered absolute and thus objective in a positive sense, but rather reified and abstract in a negative sense, disconnected from the human context in which experiences are actually lived and medicine itself is practiced. Psychiatry in the work of Karl Jaspers was ahead of the rest of medicine in recognizing this. If it is to maintain its lead, it is time for it to re-engage with the human sciences, bringing the findings of scientific evidence closer to the values of individuals and social groups, enriching the diagnostic act and improving therapeutics. Only then can psychiatry rediscover the complexity of human life and offer society an inclusive and ethical mental health service provision.

\section{Disclosure}

No conflicts of interest declared concerning the publication of this article.

\section{References}

1. Andreasen NC. Brave new brain: conquering mental illness in the era of the genome. Oxford: Oxford University; 2001.

2. Andreasen NC. DSM and the death of phenomenology in America: an example of unintended consequences. Schizophr Bull. 2007:33:108-12.

3. Fulford KWM, Morris KJ, Sadler JZ, Stanghellini G. Past improbable, future possible: the renaissance in philosophy and psychiatry. In: Fulford KWM, Morris KJ, Sadler JZ, Stanghellini G, editors. Nature and narrative: an introduction to the new philosophy of psychiatry. Oxford: Oxford University; 2003. p. 1-41.

4. Jaspers K. General psychopathology. 7th ed. Baltimore: The Johns Hopkins University Press; 1997. [Translated by Hoenig J and Hamilton M.]
5. Jaspers K. Causal and meaningful connexons between life history and psychosis. In: Hirsch SR, Shepherd M, editors. Themes and variations in European psychiatry. Bristol: John Wright and Sons Ltd; 1974. p. 80-93.

6. Jaspers K. The phenomenological approach in psychopathology. $\mathrm{Br}$ J Psychiatry. 1968;114:1313-23.

7. Maj M. Introduction: the relevance of Karl Jaspers' general psychopathology to current psychiatric debate. In: Stanghellini G, Fuchs $T$, editors. One century of Karl Jaspers' general psychopathology. Oxford: Oxford University; 2013. p. xxiv-viii.

8. Stanghellini G, Fuchs T. One century of Karl Jaspers' general psychopathology. Oxford: Oxford University; 2013.

9. Fulford KWM, Stanghellini G. Values and values-based practice. In: Stanghellini G, Broome M, Fernandez A, Fusar Poli P, Raballo A, RosfortR, editors. Handbook of phenomenological psychopathology. Oxford: Oxford University Press. Forthcoming 2018.

10. Stanghellini G, Mancini $M$. The therapeutic interview in mental health. a values-based and person-centered approach. Cambridge: Cambridge University Press. Forthcoming 2017.

11. Fulford KWM. Values-based practice: a new partner to evidence-based practice and a first for psychiatry? [editorial.] In: Singh AR, Singh SA, editors. Medicine, mental health, science, religion, and well-being. Mens Sana Monographs (MSM). 2008;6:10-21.

12. Messas G. A phenomenological contribution to the approach of biological psychiatry. J Phenomenol Psychol. 2010;41:180-200.

13. Stanghellini G, Broome M. Psychopathology as the basic science for psychiatry. Br J Psychiatry. 2014;205:169-70.

14. Stanghellini G, Rosfort R. Disordered selves or persons with schizophrenia? Curr Opin Psychiatry. 2015;28:256-63.

15. Messas G, Tamelini M, Cutting J. A meta-analysis of the core essence of the psychopathological entities: an historical exercise in phenomenological psychiatry. Hist Psychiatry. 2017 Jul 1:957154X17715414. doi: 10.1177/0957154X17715414. [Epub ahead of print]

16. Stanghellini G. Lost in dialogue. Anthropology, psychopathology, and care. Oxford: Oxford University; 2016

17. Tamelini MG, Messas GP. Phenomenological psychopathology in contemporary psychiatry: interfaces and perspectives. Rev Latinoam Psicopatol Fundam. 2017;20:165-80.

\section{Websites}

1. For an example of the wording used by NICE to describe the importance of linking up its evidence-based guidelines with the values of individual patients, see https://www.nice.org. uk/guidance/cg181 and scroll down the page to the "Your Responsibility" statement.

2. For all aspects of values-based practice, including a detailed reading guide and downloadable resources, please go to the website of the Collaborating Centre for Values-Based Practice in Health and Social Care at St. Catherine's College, Oxford: valuesbasedpractice.org.

\section{Correspondence:}

Guilherme Messas

Rua Dr. Cesário Mota Jr, 61, Vila Buarque

01221-020 - São Paulo, SP - Brazil

Tel.: +55 (11) 991049919

Fax: +55 (11) 30712014

E-mail: guilherme.messas@fcmsantacasasp.edu.br 